\title{
Research Article \\ Strength and Stiffness of Stabilized Alluvial Silt under Frost Actions
}

\author{
Haibo Wang, ${ }^{1}$ An Deng, ${ }^{2}$ and Ping Yang ${ }^{1}$ \\ ${ }^{1}$ Department of Civil Engineering, Nanjing Forestry University, Nanjing, Jiangsu 210037, China \\ ${ }^{2}$ School of Civil, Environmental and Mining Engineering, University of Adelaide, Adelaide, SA, Australia \\ Correspondence should be addressed to Haibo Wang; harbor006@foxmail.com
}

Received 26 October 2016; Revised 6 February 2017; Accepted 7 February 2017; Published 27 February 2017

Academic Editor: Hossein Moayedi

Copyright (C) 2017 Haibo Wang et al. This is an open access article distributed under the Creative Commons Attribution License, which permits unrestricted use, distribution, and reproduction in any medium, provided the original work is properly cited.

The Yellow River alluvial silt was stabilized into pavement base materials for cold regions. The stabilizing additives were cement, fly ash, and lime, which were included in a range of combinations and dosages when mixed with the silt. Freeze-thaw cyclic impacts were conducted on the treated samples to assess materials performance of withstanding the frost actions. The tests were conducted on samples cured for 7 days to up to 180 days. Test results show that the cement-fly ash-treated samples outperform the other two stabilization categories with respect to material strength and stiffness developed under both normal and frost conditions. Under the normal conditions, the material unconfined compressive (UC) strength rises to $3.0 \mathrm{MPa}$ on day 28 depending on the cement and fly ash dosage used. If subjected to frost actions, the fly ash inclusions warrant a residual UC strength value of $1.3 \mathrm{MPa}$ and above. The antifrost performance of the cement-fly ash-treated samples is related to thermal buffer capacity of the fly ash particles. Water adsorption and material soundness results agree with the strength and stiffness development. An optimal dosage was 3-6\% for the cement and 0.3 for cement to fly ash mass ratio.

\section{Introduction}

The Yellow River is the second longest river in China. As illustrated in Figure 1, the river originates in western China, flows toward the east, and empties into the Bohai Sea. When passing through the Loess Plateau situated in the midwest of China, the river erodes and thus carries downstream billions of tons of loess each year, which eventually deposits to the lower reaches of the river. The loess has deposited to a wide scope due to historical course changes and river floods, and the wide deposit scope is known as the Yellow River Flooding Area, which measures about 54,000 hectares. The loess deposits in this area are designated as the Yellow River alluvial silt.

The alluvial silt has been deemed as an important choice of fill material for infrastructures due to its vast volume and local accessibility. The infrastructures, however, are exposed to seasonal frost action with a ground surface temperature of down to $-10^{\circ} \mathrm{C}$ from December to February and up to more than $30^{\circ} \mathrm{C}$ in July and August each year [1]. These frost actions have been damaging the fill material matrix and undermining the stability of the infrastructures, including crack propagation and excessive ground deformation or even instability failures [2-4]. A solution for this concern is to stabilize the silt using cementitious additives and examine the performance of the treated silt counteracting the frost action. Altun et al. [5] stabilized sandy and clayey silt of low plasticity by using Class $\mathrm{C}$ fly ash and cement and subjected the stabilized specimens to up to seven freezing and thawing cycles. The results showed that $30 \%$ fly ash and $2 \%$ cement are the optimum dosages with respect to material strength gain, and samples with $10 \%$ fly ash and $2 \%$ cement exhibit favorable antifrost performance. Also, on common silt soils but treated with geofiber and synthetic fluid, Hazirbaba and Güllü [6] found that these new additives help maintain the materials strength after seven freeze-thaw cycles. Similar hybrid additives were attempted by Güllü and Khudir [7] who stabilized low plasticity silt using jute fiber and steel fiber together with lime and assessed the effect of freeze-thaw cycles on material strength. These studies illustrate the likelihood of stabilizing the Yellow River alluvial silt to counteract the frost action. 


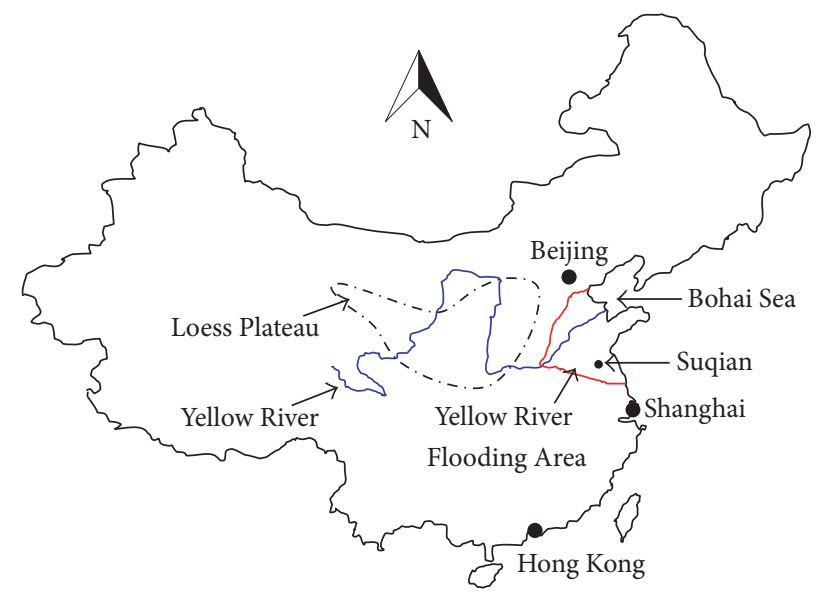

Figure 1: The Yellow River basin (not drawn to scale).

Despite the existence of studies on common silty soils, stabilizing the Yellow River alluvial silt is worth an investigation due to the silt unique characteristics. The alluvial silt has been subjected to the river weathering process and, separate from the common silty soils, exhibits special properties: round and uniform particles, low plasticity, zero to low cohesion, and hydraulic instability. The demonstrated regionspecific properties likely influence the stabilization process and lead to a design different from other common silty soils. Previous studies have also shown that the stabilization and antifrost performance are dependent on the choices of the silty soils used $[5,7]$. Similar dependence may occur to the Yellow River alluvial silt. To this end, this study adds value to the community with respect to shedding some light on how better this Yellow River alluvial silt can be stabilized under the seasonal frost environments.

In review of recent soil stabilization practices [8-14], the current study considered three common inorganic additives, Portland cement, Class F fly ash, and hydrated lime, as the stabilizers for the Yellow River alluvial silt. All of the three additives were included in a series of mass contents designed to examine the role of the additives in improving silt performance, aiming to work out a dosage for field applications. Specifically, take the cement as the major stabilizer and fly ash or lime as the minor, examining the likelihood of the minor stabilizer in improving the material performance. This is important as the hybrid scenarios likely excel in a difficult or severe environment such as the frost impact. In addition, the ingredients dosage spans a wide range so as to work out an optimum dosage. The results are supposed to be applicable to all climate environments, including regular benign conditions and severe seasonal impacts as examined in some of the previous studies. To attain this goal, this study subjected the treated soil samples to two artificial testing ambience settings: constant room temperature and freezing-thawing cyclic environments. Some critical test results including unconfined compressive (UC) strength, material mass loss, and water absorption observed under the respective testing ambience settings are presented and discussed.

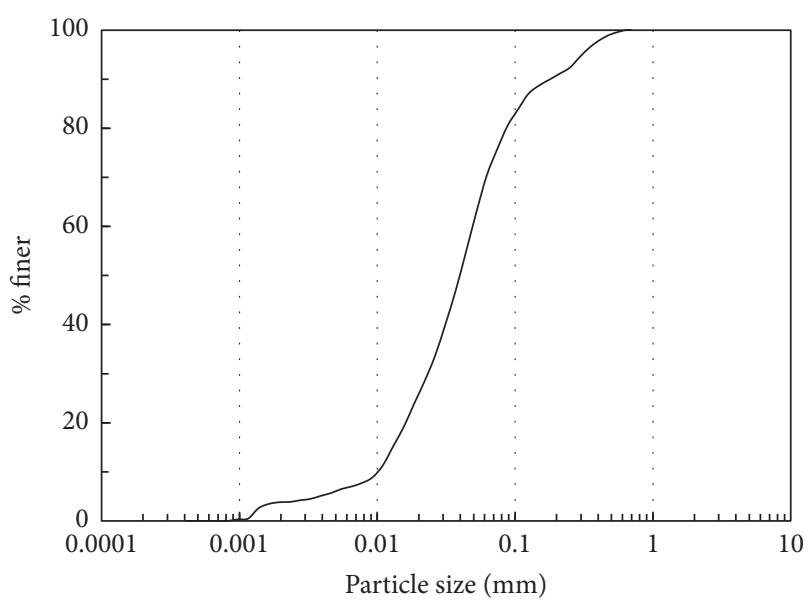

Figure 2: Grain size distribution of soil sample.

\section{Materials and Methods}

2.1. Materials. The Yellow River alluvial silt was recovered from Suqian of Jiangsu Province, a midsize city situated in the south part of the Yellow River Flooding Area (Figure 1). Figure 2 shows the soil particle size distribution curve. Major soil index properties are summarized in Table 1. The particle size distribution was measured by a laser particle size analyzer Mastersizer 2000 which enables size analysis of both the coarse and the fine fractions of the silt. The vendor's manual specifies that a volume of sample flows across the focused beam of laser light and the intensity of light scattering is recorded, analyzed, and related to particles size. The Atterberg limits results for the alluvial silt sample are $22 \%$ for the plastic limit $I_{P}$ and $33 \%$ for the liquid limit $I_{L}$. The silt is classified as ML sandy silt of low plasticity with $4.8 \%$ clay, according to the Unified Soil Classification System. Undisturbed native soil samples exhibit low bearing capacity with a California Bearing Ratio $=2.6 \%$ and UC strength $=$ $0.11 \mathrm{MPa}$. Three cementitious additives were used, Portland cement, Class F fly ash, and hydrated lime, to stabilize the silt. The cement is rated as CEM I $32.5 \mathrm{R}$ and has a density of $3,060 \mathrm{~kg} / \mathrm{m}^{3}$, specific area of $3,460 \mathrm{~cm}^{2} / \mathrm{g}$, initial setting time of $2.98 \mathrm{~h}$, and final setting time of $5.67 \mathrm{~h}$. The fly ash was collected from Xuzhou Thermal Power Plant. It has a density of $2,210 \mathrm{~kg} / \mathrm{m}^{3}$, specific area of $2,251 \mathrm{~cm}^{2} / \mathrm{g}$, and maximum dry density of $1,320 \mathrm{~kg} / \mathrm{m}^{3}$ obtained through the Proctor test. The Proctor test was conducted in accordance with China Standard for Soil Test Method [15]. The hydrated lime showed activity of $80 \%$. Significant material composition differences are summarized in Table 2.

The additives were added in three combinations: cement alone, cement-fly ash combined, and cement-lime combined. All of the three combinations were blended together with corresponding optimum moisture contents which were obtained through the soil Proctor compaction tests. Each combination included a range of dosages with details shown in Table 3. The additive dosages are presented as percentage of dry soil mass. The dosages were designed to make the effect of additives content on the performance of the treated soil samples stand 
TABLE 1: Soil index properties.

\begin{tabular}{lc}
\hline Property & Value \\
\hline Specific gravity & 2.70 \\
Sand (\%) & 22.9 \\
Silt (\%) & 72.3 \\
Clay (\%) & 4.8 \\
Liquid limit (\%) & 33 \\
Plastic limit (\%) & 22 \\
Plasticity index & 11 \\
Maximum dry density $\left(\mathrm{kg} / \mathrm{m}^{3}\right)$ & 1.78 \\
Optimum moisture content $(\%)$ & 15.7 \\
USCS classification & $\mathrm{ML}$ \\
\hline
\end{tabular}

TABLE 2: Chemical compositions of materials.

\begin{tabular}{lcccc}
\hline \multirow{2}{*}{ Oxide } & \multicolumn{4}{c}{ Percentage by mass (\%) } \\
& Silt & Fly ash & Cement & Lime \\
\hline $\mathrm{SiO}_{2}$ & 61.95 & 50.11 & 21.40 & - \\
$\mathrm{Fe}_{2} \mathrm{O}_{3}$ & 3.65 & 5.25 & 2.69 & 0.4 \\
$\mathrm{MgO}$ & 2.54 & 1.61 & 2.02 & 6.8 \\
$\mathrm{CaO}$ & 7.10 & 2.64 & 63.65 & 72.9 \\
$\mathrm{Na}_{2} \mathrm{O}$ & 1.15 & 0.57 & 0.31 & - \\
$\mathrm{K}_{2} \mathrm{O}$ & 2.01 & 0.45 & 0.67 & - \\
$\mathrm{Al}_{2} \mathrm{O}_{3}$ & 12.42 & 27.2 & 4.58 & 0.8 \\
$\mathrm{SO}_{3}$ & - & 7.05 & 2.63 & - \\
Loss on ignition & 6.95 & 5.19 & 5.14 & - \\
\hline
\end{tabular}

Note. - : not tested.

out. For instance, for the cement-treated silt, the cement content falls in the choices of $3 \%, 6 \%$, and $8 \%$; for the cementfly ash-treated silt, the fly ash content increases from $7 \%$ to $15 \%$ with the cement content remaining unchanged at $3 \%$, or from $6 \%$ to $30 \%$ with the cement content remaining unchanged at $6 \%$. The chosen dosages were also designed into levels in line with those adopted in existing studies (e.g., $[10,12,16])$ and so help compare the test results.

2.2. Sample Preparation. Oven-dry silt and the additives were proportioned based on the designed dosages shown in Table 3. The dry mixtures were thoroughly blended in a mixer of 60 liters. The mixer capacity is about six times the volume of the intended ingredients of one batch and so offers decent room to facilitate motions of the ingredient particles and thus mixture uniformity. The weighed ingredients were fed into the mixer in dry states and in sequential equal portions. It is well acknowledged that the dry mixing process outperforms the wet mixing process with respect to achieving mixture uniformity when dealing with blending multiple ingredients. In addition, feeding the ingredients in portions avoids possible clods, clumps, or segregation. To confirm the mixture uniformity, the standard deviation of the UC test results was assessed. At least four samples from the same batch were tested and a value of $15 \%$ for the standard deviation was applied. If the value is above $15 \%$, additional samples were tested until the criterion was satisfied. The criterion is a
TABLE 3: Additives used to treat silt.

\begin{tabular}{lcccc}
\hline Sample & Cement (\%) & Fly ash (\%) & Lime (\%) & Water (\%) \\
\hline C3 & 3 & 0 & 0 & 16.0 \\
C6 & 6 & 0 & 0 & 15.9 \\
C8 & 8 & 0 & 0 & 15.9 \\
C3FA7 & 3 & 7 & 0 & 15.4 \\
C3FA10 & 3 & 10 & 0 & 15.3 \\
C3FA15 & 3 & 15 & 0 & 15.0 \\
C6FA6 & 6 & 6 & 0 & 16.4 \\
C6FA10 & 6 & 10 & 0 & 15.6 \\
C6FA20 & 6 & 20 & 0 & 15.0 \\
C6FA30 & 6 & 30 & 0 & 14.9 \\
C8FA20 & 8 & 20 & 0 & 15.8 \\
C1.6L4 & 1.6 & 0 & 4 & 16.8 \\
C2L4 & 2 & 0 & 4 & 16.9 \\
C3L4 & 3 & 0 & 4 & 17.0 \\
C3L7 & 3 & 0 & 7 & 17.3 \\
C3L9 & 3 & 0 & 9 & 17.7 \\
\hline
\end{tabular}

normal convention used to confirm consistency for UC test results of a geomaterial. The corresponding water content shown in Table 3 was included into the dry mixture to form a paste which was then subjected to further blending efforts. The complete blending process lasted about 30 minutes when no major clumps larger than $5 \mathrm{~mm}$ were observed. The fresh paste was then poured into a cylindrical steel mold of $50 \mathrm{~mm}$ diameter and $100 \mathrm{~mm}$ height. This sample dimension helps attain a uniform thermal profile within the sample when altering ambient temperature and therefore minimize the effect of transient freezing [17]. A static sample tamping process, as specified in standard ASTM D5102 [18], was adopted to achieve $96 \%$ degree of compaction. This degree of compaction meets the specifications stipulated for common civil infrastructures. Efforts such as use of multiple tamping devices were undertaken to compact the samples of a batch before the cement initial setting time. Calculate the mass and volume of the soil needed to achieve the $96 \%$ degree of compaction, feed the soil into the mold, and compress the soil by the plunger to the desirable volume. Once the sample was formed and extruded from the mold, it was then wrapped with a waterproof membrane and stored in a curing chamber with a constant temperature of $20 \pm 1^{\circ} \mathrm{C}$ and relative humility of $96 \pm 2 \%$ until a testing date.

2.3. UC Strength Test. The UC strength test was conducted on samples cured for 7, 28, and 180 days, respectively. The UC strength test was also conducted on cured samples after the designed freezing-thawing cycles. Both tests referred to the standard ASTM D5102 (2016). In a UC strength test, the sample was compressed at a rate of $1 \mathrm{~mm} / \mathrm{min}$. The rate of strain was chosen so that the time to failure was about 15 minutes. The UC strength was the peak stress obtained during the test. At least four replicate samples were tested for each examined dosage and, as mentioned before, a criterion of $15 \%$ standard deviation applies to the UC strength results before averaging them into the UC strength value for this dosage. 
TABLE 4: Freezing-thawing program.

\begin{tabular}{|c|c|c|c|}
\hline \multirow[b]{2}{*}{ Sample } & \multicolumn{3}{|c|}{ Freeze-thaw cycles } \\
\hline & $\begin{array}{l}\text { After 28-day } \\
\text { curing }\end{array}$ & $\begin{array}{l}\text { After } 38 \text {-day } \\
\text { curing }\end{array}$ & $\begin{array}{l}\text { After } 180 \text {-day } \\
\text { curing }\end{array}$ \\
\hline $\mathrm{C} 3$ & 1,3 & & \\
\hline C6 & $1,3,5,7,9$ & & \\
\hline C3FA15 & 1,3 & $5,7,9$ & \\
\hline C6FA10 & 1,3 & $5,7,9$ & $1,3,5,7,9$ \\
\hline C6FA20 & 1,3 & $5,7,9$ & \\
\hline C6FA30 & 1,3 & $5,7,9$ & \\
\hline $\mathrm{C} 2 \mathrm{~L} 4$ & $1,3,5,7,9$ & & \\
\hline C3L4 & $1,3,5,7,9$ & & \\
\hline C3L7 & $1,3,5,7$ & & \\
\hline C3L9 & $1,3,5$ & & \\
\hline
\end{tabular}

2.4. Freezing and Thawing. The freezing and thawing processes were conducted in accordance with ASTM D560 [19]. Upon a curing date, the soil samples were unwrapped, weighed, inundated in water for 24 hours to saturate the samples, and reweighed. The saturated samples were then kept in a freezer at $-15^{\circ} \mathrm{C}$ for $24 \mathrm{~h}$ to sustain freezing. The temperature values were determined to suit the local (i.e., Suqian city) climate conditions documented in the past ten years. Next, the sample was transferred to the same curing chamber for 2-3 hours until completely thawed and then hydrated in the curing chamber for another 21-22 hours. These steps formed one freeze-thaw cycle. Sufficient samples, at least 36 cylinders for one dosage, were prepared in order to account for the number of tests conducted under varying freeze-thaw cycles. Sample and test details are shown in Table 4. The shown test program considered three curing ages: 28 days, 38 days, and 180 days. After each curing age, the samples were subjected to a certain number of continuous freeze-thaw impacts and then UC strength tests. In the testing program, sample C6FA10 was subjected to all three curing ages. This is to examine the time-dependent performance of the fly ash which is known to possess a pozzolanic reaction in the long term. The 28-day and 38-day curing times were designed to examine strength development at early ages. Scaling occurs to stabilized soils when exposed to freeze-thaw impacts and this is assessed as a material property known as soundness. To assess the material soundness against the frost actions, all samples were weighed at the end of the designed cycles and before being subjected to the UC tests where possible.

\section{Results and Discussion}

3.1. Compaction. The Proctor compaction test results are shown in Figure 3. Values are shown in terms of additives and dosages used to stabilize the Yellow River alluvial silt. Figure 3(a) shows higher optimum moisture content (OMC) and lower maximum dry density (MDD) when stabilizing the silt with the cement. These results are in agreement with past studies such as that by Tripura and Singh [20]. The cement dependence of the compaction curves arises from noticeable water absorption capacity of the cement in relation to the silt. As a result, an extra volume of water is required to lubricate solid particles and attain the optimum compaction of the mixtures. The OMCs, MDDs, and the compaction curves, however, remain similar for the series of cement-treated silt samples. With the cement content of $3 \%$ to $8 \%$, the values range from $15.7 \%$ to $16.1 \%$ for the OMCs and from 1,780 to $1,766 \mathrm{~kg} / \mathrm{m}^{3}$ for the MDDs.

The cement-lime-treated and cement-fly ash-treated samples show different trend lines. For the cement-limetreated samples, the OMCs increase and the MDDs decrease with the increase of the lime content, if the cement content remains at $3 \%$. This implies that the compaction is sensitive to the lime content. Similar sensitivity occurs to the cement-fly ash-treated samples. As what occurred in earlier studies [10, $16,21]$, the decreases of MDDs occur due to the lower specific gravity of the fly ash and the lime-the replacement of soil particles in a given volume by particles of fly ash or lime of lower specific gravity compared to that of the soil particles. It is noteworthy that the cement-fly ash-treated samples show interesting trends for the OMCs. The OMC values increase for sample C6FA6 and decrease for the other series of samples. The trend lines differ from those obtained by Kumar et al. [10] which shows increasing OMCs (28-37\%) with an increase of fly ash (0-20\%). Their study used similar Class F fly ash but high plasticity black cotton soil with $I_{P}=49.65 \%$ and $I_{L}=68 \%$. The values are higher than corresponding values of the Yellow River alluvial silt shown in Table 1 . This implies that the soil plasticity likely influences the OMC values. The higher the plasticity, the higher the OMCs. This argument is acceptable as the additional moisture content works as a lubricant into the surface of additional clay particles.

An explanation for the "discrepancy" on the compaction curves among the three stabilization categories arises from the varying $\mathrm{CaO}$ contents in the additives. As shown in Table 2, a significant difference exists with respect to the $\mathrm{CaO}$ contents among the three additives: $2.64 \%$ for the fly ash, $63.65 \%$ for the cement, and $72.9 \%$ for the lime. In contact with water, the content of $\mathrm{CaO}$ determines the water volume needed to form calcium hydroxide, an ingredient for pozzolanic reactions. This means that the need of the water volume for the fly ash-based samples is not as significant as that for the cement- or the lime-based samples in order to enable thorough pozzolanic reactions. The need for water becomes less noticable when increasing the fly ash contents. Conversely, the need for the water volume reduces when increasing the fly ash fraction in the cement-fly ash-treated samples. In the meantime, the spherical nature of the fly ash particles facilitates packing of the mixture which further offsets the need for water. As a result, the more the fly ash content, the less the water volume for the cement-fly ash-treated samples, in relation to the cement- or cement-lime-treated samples, needed to compact the mixture.

3.2. UC Strength (Without Frost Actions). The UC strength results are shown in Figure 4. Values are shown for samples without the frost actions and categorized in terms of the curing times and the additives used. Varying strength levels are obtained for the silt, dependent on the additives content 


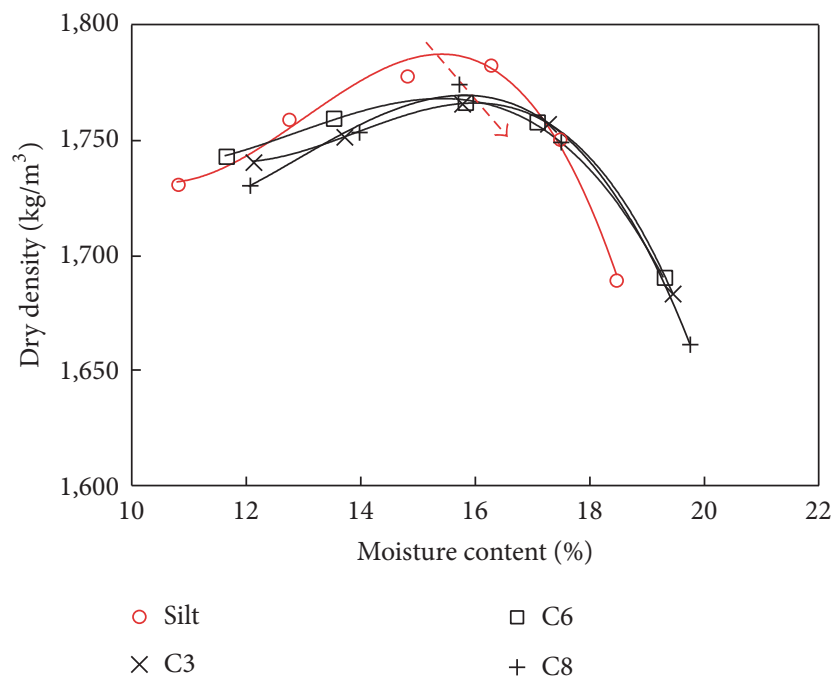

(a)

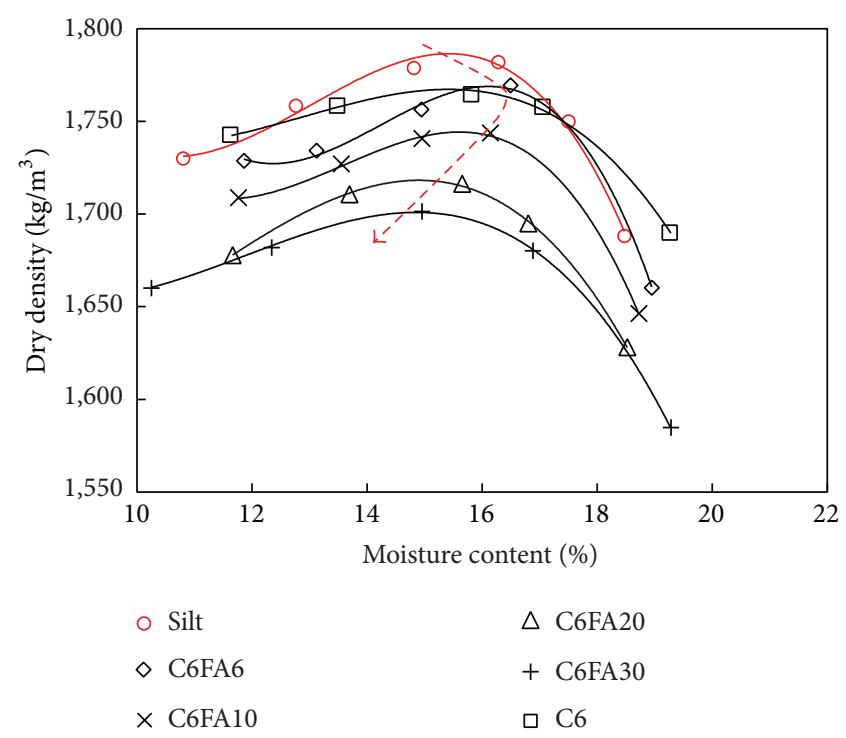

(b)

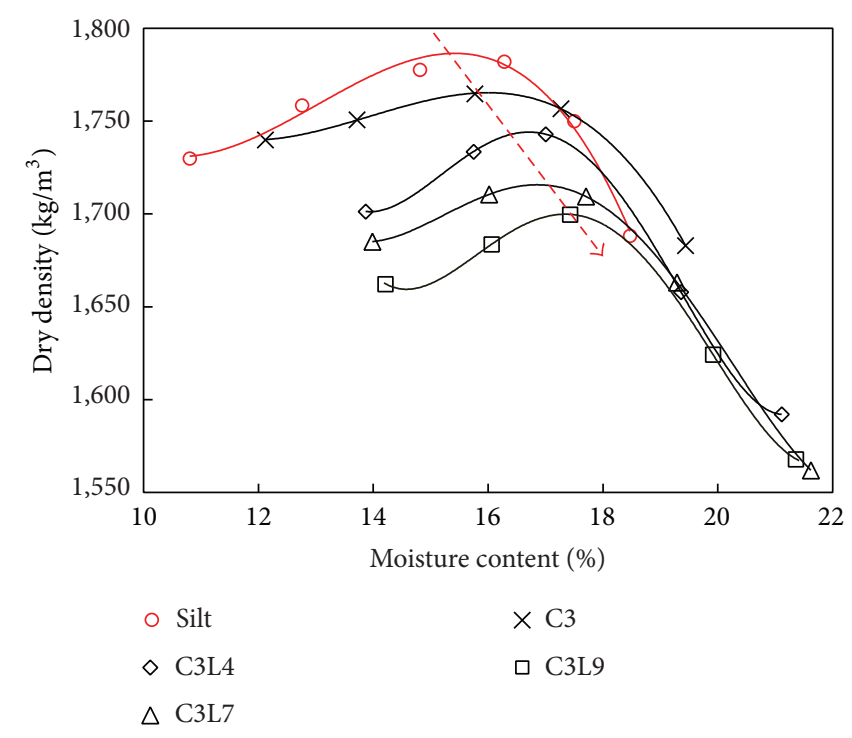

(c)

FIGURE 3: Proctor compaction test results: (a) cement-treated silt, (b) cement-fly ash-treated silt, and (c) cement-lime-treated silt.

used. The cement-treated samples (C3, C6, and C8) show UC strength increase linearly proportional to the increase of the cement content. The values fall in the ranges of $0.59 \mathrm{MPa}$ to $1.48 \mathrm{MPa}$ at 7 days and $0.68 \mathrm{MPa}$ to $1.67 \mathrm{MPa}$ at 28 days. This implies that moderate strength increases ( $14.2 \%$ on average) are gained from 7 days to 28 days, if the sample cement content remains the same. The strength develops due to the cement hydration creating a matrix of gel (i.e., the ettringite) to solidify the soil particles; and the gel grows over time. The strength values and the increase rates agree with the results for other cement-treated soils such as clay [22], marine sediments [23], and silty sand and clayey silt [24], where the cement was of similar contents.

Figure 4 shows that the 7-day UC strength of a cement-fly ash-treated sample is close to that of its dosage-corresponding cement-treated sample, such as $\mathrm{C} 3 \mathrm{FA} 7$ versus $\mathrm{C} 3$ and C6FA10 versus C6. This agreement does not occur to the samples cured to 28 days when a cement-fly ash-treated sample shows UC strength significantly higher than that of its dosagecorresponding cement-treated sample. The reason is that, for the cement-fly ash-treated samples, significant strength increase $(155.3 \%$ overall) is attained from the 7 -day curing to the 28-day curing, where the cement and fly ash contents remain the same. The increase is merely $14.2 \%$ for the cementtreated samples. For the cement-fly ash-treated samples, the 28 -day strength falls in the ranges of $1.46 \mathrm{MPa}$ to $2.93 \mathrm{MPa}$. These comparisons suggest that the fly ash contributes to the strength development after the 7-day curing, which has been confirmed in similar fly ash stabilization studies $[25,26]$. This strength dependence on the fly ash is associated with 


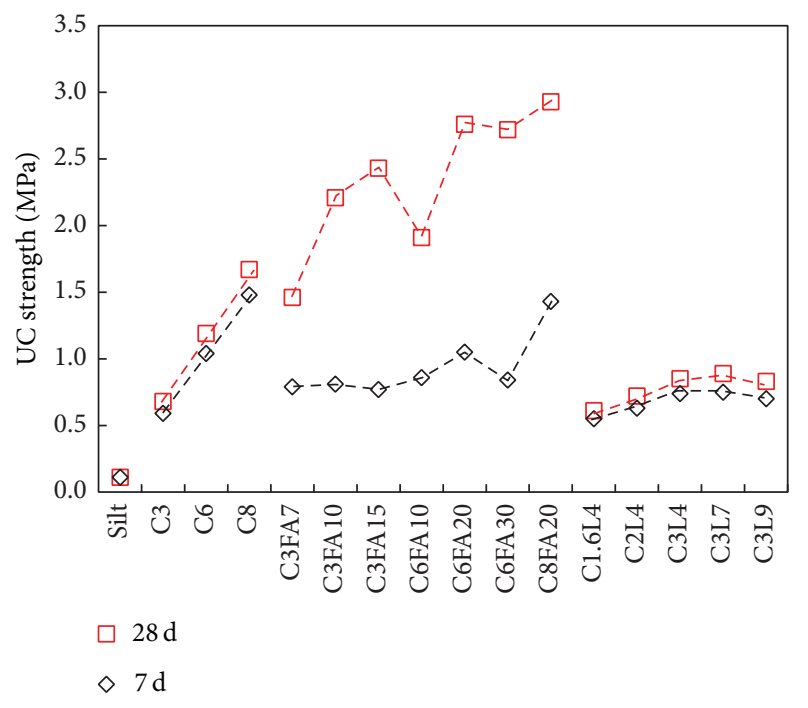

FIGURE 4: UC strength of stabilized samples without frost actions.

fly ash pozzolanic properties. The fly ash is a pozzolanic material, which when mixed with Portland cement and water reacts with calcium hydroxide released by the hydration of Portland cement to produce calcium silicate hydrates and calcium aluminate hydrates, improving the strength of the stabilized materials. These pozzolanic reactions are timedependent processes and often remain noticeably active after 90 days of curing [27]. The effect of the fly ash on the strength development is also clear for samples with different fly ash contents. For instance, on the 28th day, the UC strength of the cement-fly ash-treated samples increased with the increase of the fly ash content where the cement content remained the same, such as $2.21 \mathrm{MPa}$ for sample C3FA10 versus $1.46 \mathrm{MPa}$ for sample C3FA7.

It is noteworthy that a strength "drop" appears in sample C6FA10 on day 28. The UC strength for this sample is $1.91 \mathrm{MPa}$. The strength for the neighboring samples is $2.43 \mathrm{MPa}$ for sample C3FA15 and 2.76 for sample C6FA20. Although the differences are tolerable and the strength falls in the working range for backfill materials, it is of some value to research the possible details behind the strength inconsistency. There are no absolute answers. One possible explanation is the level of pozzolanic reactions versus the fly ash contents. The 28-day pozzolanic reactions are dependent on the fly ash contents due to fly ash's relatively slow hydration processes. The hydration processes rely on the calcium hydroxide released by the hydration of the cement to form additional calcium silicate hydrate and other cementitious compounds and then build up the strength. Seeing the increase of the cement content and the decrease of the fly ash content for sample C6FA10 in relation to sample C3FA15, the fly ash, as the source of pozzolan, is likely in short for the hydration processes and the pozzolanic reactions are not as thorough as sample C3FA15. Having increased the fly ash content by $10 \%$, sample C6FA20 improves the ingredients fraction and thus the hydration processes and the strength. This argument is supported by comparing sample C6FA10 with sample C3FA10. The latter gives rise to a relatively less and probably appropriate level of calcium hydroxide through the cement hydration processes than the former does. The calcium hydroxide level is appropriate in that it enables the $10 \%$ fly ash pozzolanic reactions without leaving a significant excess of free calcium hydroxide, a less desirable hydration product due to its dissolvability. The fly ash to cement ratio is discussed subsequently.

No clear strength is gained from the increase of the lime content or the curing period for the cement-lime-treated samples. This implies that lime plays a less significant role in improving strength for the silt. Similar less significant strength development for lime-treated silt or clay was reported by Sakr et al. [28] and Le Runigo et al. [29]. Scholen [30] suggested that lime is sensitive to accessible water volume and the sensitivity causes insignificant strength development where the water volume such as the OMC is less than the volume desired for complete hydration. This suggestion is somehow in line with the results obtained in the current study. The chosen water contents for the cement-lime-treated samples were $\mathrm{OMC}=16.8-17.7 \%$ (Table 3 ). The water contents were less than the water to lime ratio, that is, 0.3 or higher [31], desired to enable satisfactory pozzolanic reactions, and so involve less strength development. On a separate perspective, the lime-based samples have the potential to further develop strength given the access to moisture, which possibly hydrates the free lime, and create additional gel.

Normalization was conducted on additives dosage for the cement-fly ash-treated samples. Define mass ratio $m$ as the fly ash content to the cement content. The optimum $m$ value is where the UC strength approaches a peak value. The assessment for this optimum $m$ value helps weigh the importance of the fly ash against the cement and thus suggests an optimal dosage where appropriate. Figure 5 shows the $m$ values versus the UC strength. For the three cement contents 3\%, 6\%, and $8 \%$, 7-day samples show an approximately flat development of the UC strength with the increase of $m$ values; 28-day samples show an optimum value $m=5.0$ if cement $=3 \%$ and $m=3.3$ if cement $=6 \%$. This reflects that the optimum $m$ value is dependent on the cement content. The dependence of the optimum $m$ value on the cement content indicates that a smaller fly ash to cement ratio is needed to achieve better strength development when the cement content increases. A range of $m=5$ to 3 is plausible where the cement content falls in the range of $3 \%$ to $6 \%$. This range is subject to improvement where additional test results are accessible.

3.3. UC Strength (Postfrost Actions). The UC strength results for all of the stabilized samples after frost actions are aggregated in Figure 6. Values are categorized in terms of the curing periods and the additives used. Overall, the cement-fly ashtreated samples show better postfrost performance than the cement-treated samples. The cement-lime-treated samples show performance similar to the cement-treated samples. This means that the fly ash improves material capacity counteracting the frost impact. Close UC strength values (0.1 to $0.2 \mathrm{MPa}$ ) were obtained between the cement- and cementlime-treated samples after the 9th cycle (shown as converged ends for the bottom group of lines). After the same 9th cycle, the cement-fly ash-treated samples show varying strength 


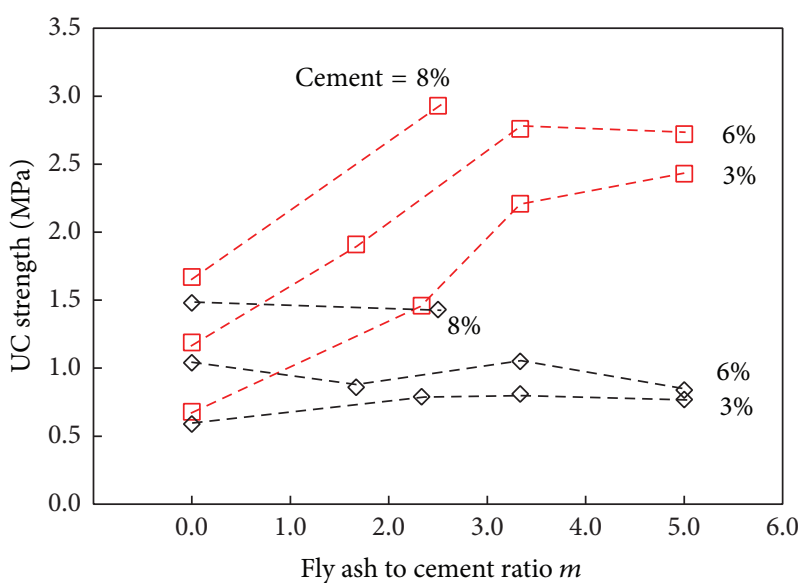

$\square 28 \mathrm{~d}$ $\diamond 7 \mathrm{~d}$

FIGURE 5: UC strength versus fly ash to cement mass ratio.

values (1.3 to $2.2 \mathrm{MPa}$ ) dependent on the fly ash contents. The higher the fly ash content, the higher the strength. This implies that the fly ash inclusion contributes to the material strength increase and counteracts the frost action. Similar results were reported by Altun et al. [5] for fly ash stabilized slit samples. The better antifrost performance of the cementfly ash-treated samples arises partly from the hollow spherical nature of the fly ash particles. The fly ash consists of particles that resulted from the cooling of molten droplets of fused material contained within the exhaust gases leaving a combustion furnace where coal is burned to provide power. Fusion of silicate minerals results in the formation of hollow glassy spherical particles. The hollow spheres are elastic, light, and sometimes waterproof, which creates a foam matrix benefiting the stabilized silt counteracting the frost actions, as illustrated in Figure 7. The foam matrix helps buffer the volumetric increase that resulted from the ice lensing processes, which otherwise cracks or damages the silt matrix stabilized by other additives such as the cement. Similar concept of counteracting frost actions has been successfully applied to other foamed concrete products [32]. The cement or the lime, however, does not possess the hollow foamed structure, nor the buffering capacity when subjecting the samples to the freezing processes. To make it worse, lime-based geomaterials are expected to undergo a certain degree of swelling and soften when in contact with water. This means further deterioration in the thawing phase. As mentioned before, this observed heave is related to the additional generation of ettringite due to the existence of free lime.

In Figure 6, the UC strength drops with the increase of the freeze-thaw cycles for the cement-fly ash-treated samples. The drops are on average $16.8 \%$ after the 1 st cycle, $13.4 \%$ from the 1st to the 3 rd cycle, $8.1 \%$ from the 5 th to the 7 th cycle, and $25.8 \%$ from the 7 th to the 9 th cycle. These drops indicate that the strength losses become pronounced after the 1st freezing-thawing impact and worse after the 7 th. These observations are in agreement with the test results reported by $\mathrm{Qi}$ et al. [33]. The cement-lime-treated samples show

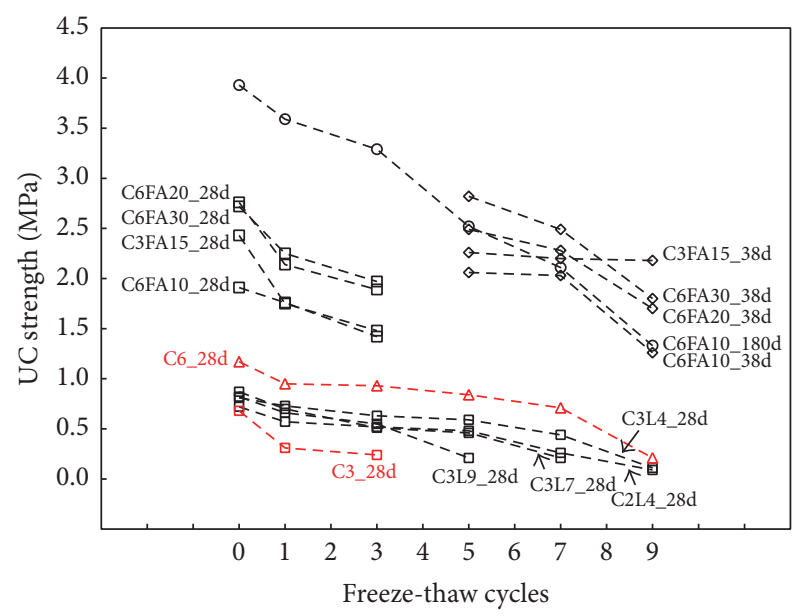

Figure 6: UC strength of stabilized samples after frost actions.

strength drops different from the cement-fly ash-treated samples. The differences lie in the drop percentage versus the cycle number. The drops are on average $17.4 \%$ after the 1 st cycle, $16.6 \%$ from the 1 st to the 3 rd cycle, $21.4 \%$ from the 3 rd to the 5 th cycle, $41.9 \%$ from the 5 th to the 7 th cycle, and $71.2 \%$ from the 7 th to the 9 th cycle. The significant drops occur after the 5th cycle-weakening earlier and worse in magnitude than the cement-fly ash-treated samples. The accelerated material deterioration is likely associated with the larger pore space of the cement-lime samples. The cement-lime samples show an average void ratio of 0.57 versus 0.52 for the cementfly ash-treated samples and 0.54 for the cement-treated sample. As suggested by Khoury and Zaman [34], the larger pore space is open to water access and thus vulnerable to ice lens evolutions which in turn induce cracking or fissuring due to icing pressures increased within the soil pores. As a result, additional pore spaces form and impair the soil matrix through further freezing-thawing iterations.

The curing processes help develop the UC strength and counteract strength drops caused by the frost actions where the fly ash is used. Despite being subjected to two more frost cycles, the 38-day cement-fly ash samples remain sound and give rise to UC strength higher than or equal to the strength of corresponding 28-day samples, as shown in Figure 6. This means that the additional 10-day curing time contributes to strength gain. This logic for the curing time versus the strength seems to not follow where a longer curing period is in place, for example, samples C6FA10_180 versus C6FA10_38. Both samples use the same dosage but were cured for different periods: 180 days for the former and 38 days for the latter. Both give rise to strength of similar level after the 7 th freezing-thawing cycle, as well as the 9th cycle. This suggests two presumptions: (i) samples C6FA10_180 and C6FA10_38 attain similar UC strength before being exposed to the first freeze-thaw impact. Similar strength losses occur to the two sets of samples through the subsequent impacts. As a result, the UC strength values agree with each other after the 7 th cycle, so do the strength values after the 9th cycle. Or (ii) before the 1st impact, sample C6FA10_180 attains strength higher than sample C6FA10_38 does. Despite starting with 


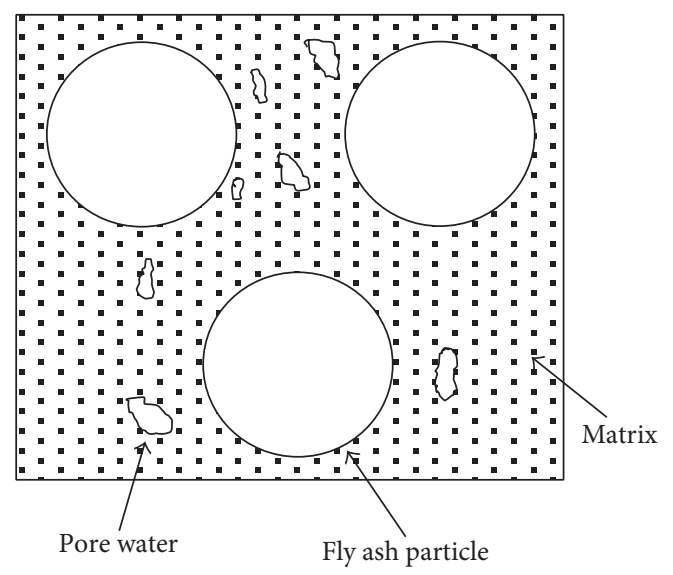

(a)

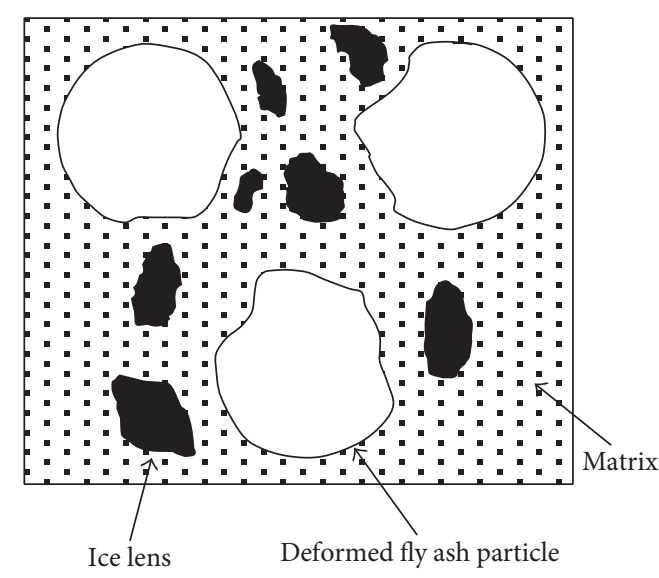

(b)

FIGURE 7: Schematic of foamed matrix: (a) before frost action and (b) after frost action.

the higher strength, sample C6FA10_180 deteriorates more severely at each impact and, after the 7th impact, ends up being close in strength to sample C6FA10_38. Presumption (ii) seems less plausible, as this presumption is inconsistent with the strength evolution of sample C6FA10_28. Sample C6FA10_28 gives rise to lower strength levels in relation to sample C6FA10_180 from the start and throughout corresponding impacts. Taking on presumption (i) means an insignificant strength having developed after the 38-day curing age.

Hori and Morihiro [35] and Yarbaşi et al. [36] linked material antifrost performance with material brittlenessthe more brittle the material is, the more susceptible it is to cracking when frozen. This point somehow agrees with the shown test results: the higher the material strength (brittleness), the steeper the strength reduction curves, and vice versa. Although the relationship is noted between the material brittleness and the antifrost performance, no optimal dosage is clearly suggested from the curves of the UC strength versus the freeze-thaw cycles as shown in Figure 6. Sample C3FA15, when cured for 38 days, shows marginal strength loss throughout the 5th, 7th, and 9th cycle and is likely identified as a dosage of preference. If cured for 28 days, however, this sample shows less favorable performance in the first three cycles. In view of this, the preferred dosage is subject to further verification tests such as subjecting the 38day samples to 1 and 3 frost cycles and assessing respective UC strength losses.

To examine ductile behavior of the stabilized silt, the stress-strain curves obtained in the UC strength tests are obtained and presented in Figure 8. The curves are categorized in terms of the freeze-thaw cycle number and drawn at the same scale in order to assess the effect of the frost actions across samples. The stress-strain curves are plotted for representative samples: C6FA10_28, C6FA10_38, C6FA10_180, C6_28, C3_28, and C3L4_28. These samples are chosen because of their comparable dosages such as C6FA10 versus C6 and C3L4 versus C3 which enable examination of the effects of the fly ash or lime on top of the cement. The dosage of $10 \%$ for the fly ash is chosen as this percentage is the least out of the series of cement-fly ash-treated samples and helps assess changes that occurred to the samples ductile behavior where a small content of fly ash is included. So does the $4 \%$ for the lime. The curves demonstrate distinct stress-strain characteristics among the samples. The fly ash inclusion clearly provides an increase in soil strength and ductility: higher peak strength and larger strain at failure. In addition, the ductility of the cement-fly ash-treated samples remains pronounced after respective frost actions. The cement- and the cement-lime-treated samples, however, show relatively less ductility. The demonstrated ductile behavior is in agreement with the aforementioned antifrost performance of the samples. Better ductility means a higher level of ability of the sample to deform under stress, or greater extent to which the sample can be plastically deformed to large strains without macroscopic fracturing or failure. To these ends, the fly ash outperforms the lime with respect to amending cemented samples and improving samples ductility and antifrost performance.

To gain further insights into the stress-strain characteristics, in particular material stiffness, secant modulus for each of the samples is plotted against corresponding peak UC strength, as shown in Figure 9. The secant modulus is the slope of the line from the origin to a point on a stress-strain curve where the stress is half the peak UC strength. The moduli are plotted in terms of the frost actions the samples are subjected to. In each plot, the moduli are categorized in terms of the additives used to treat the alluvial silt. It is shown that the cement-fly ash-treated samples are overall stiffer than the other two treatment categories when subjected to the same frost actions. For instance, after the 1st freeze-thaw cycle, the secant modulus ranges from $67 \mathrm{MPa}$ to $102 \mathrm{MPa}$ for the cement-fly ash-treated samples and $37 \mathrm{MPa}$ to $41 \mathrm{MPa}$ for the cement-lime-treated samples, depending on the dosages used. After the 9th cycle, the cement-fly ash-treated samples give rise to secant modulus even slightly higher than that of the respective intact samples of the other two treatment categories. It is noted that the secant moduli for all the three 


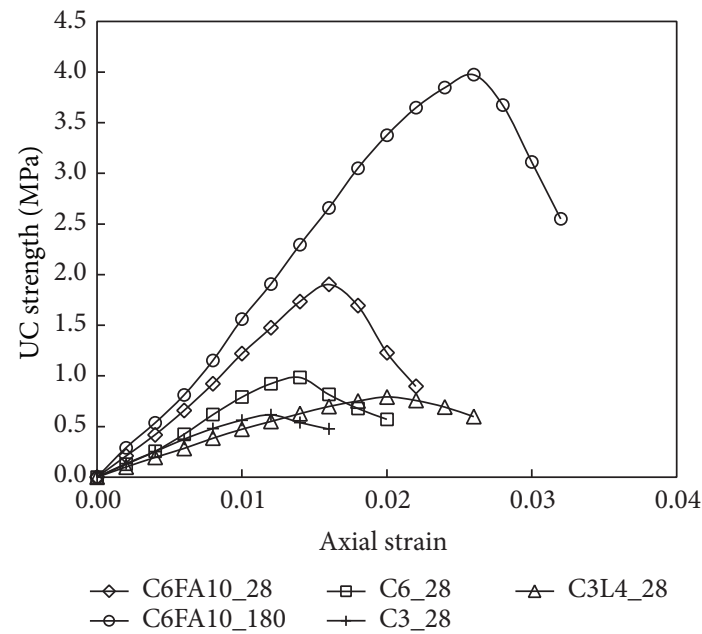

(a)

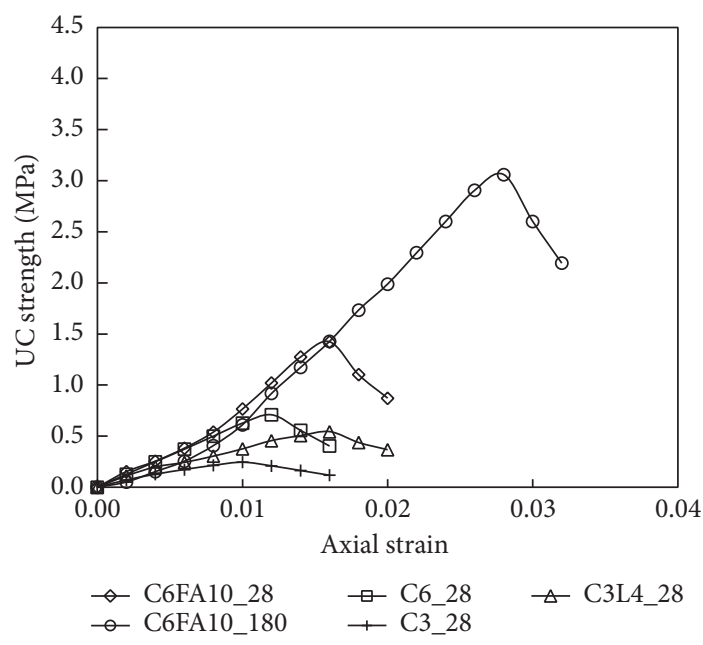

(c)

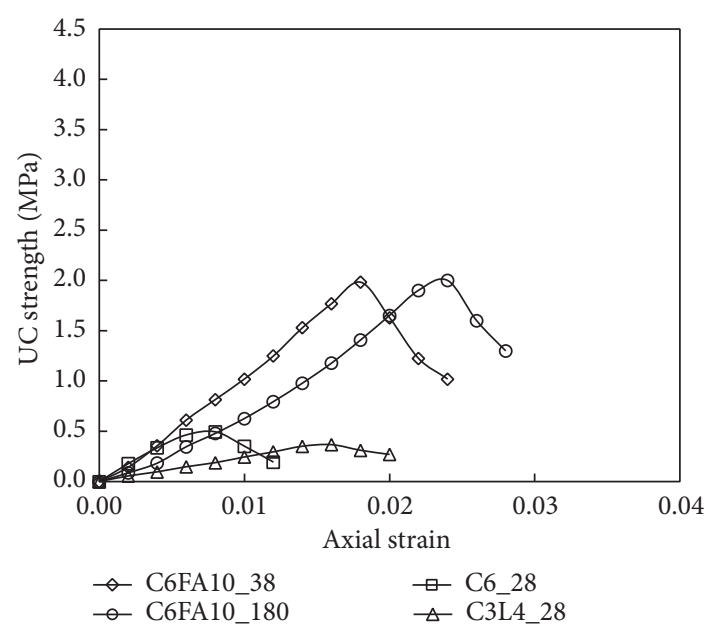

(e)

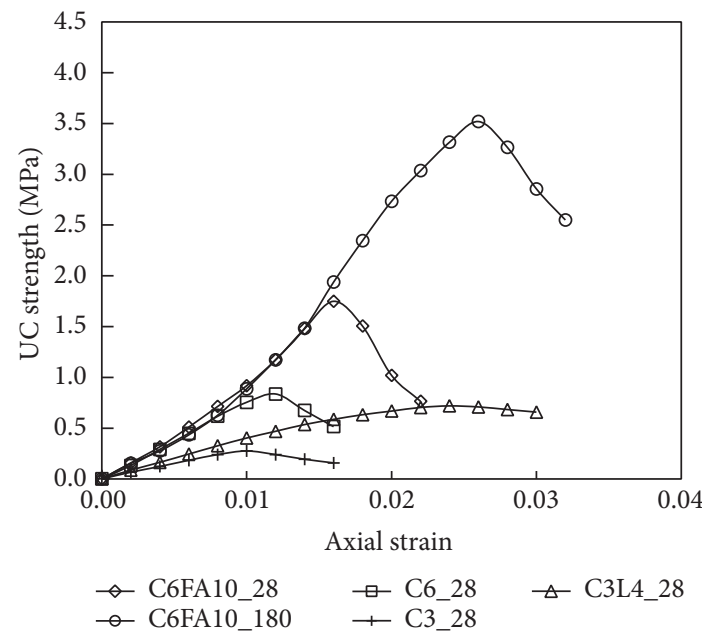

(b)

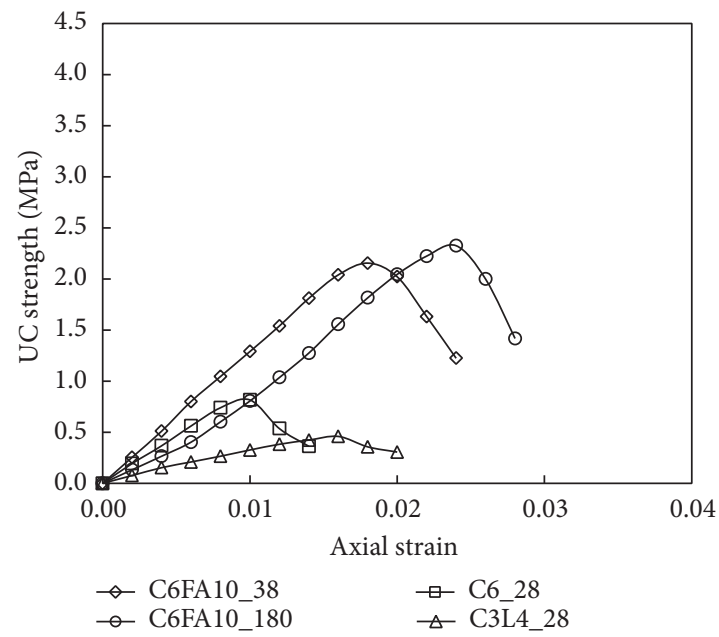

(d)

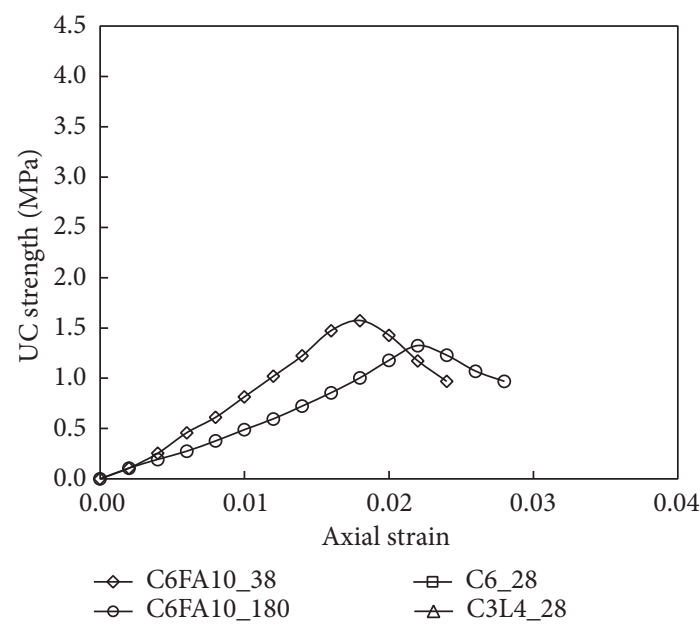

(f)

FIGURE 8: Stress-strain curves in UC strength tests drawn at the same scale for samples subjected to different freeze-thaw cycles: (a) no frost actions, (b) 1 cycle, (c) 3 cycles, (d) 5 cycles, (e) 7 cycles, and (f) 9 cycles. 


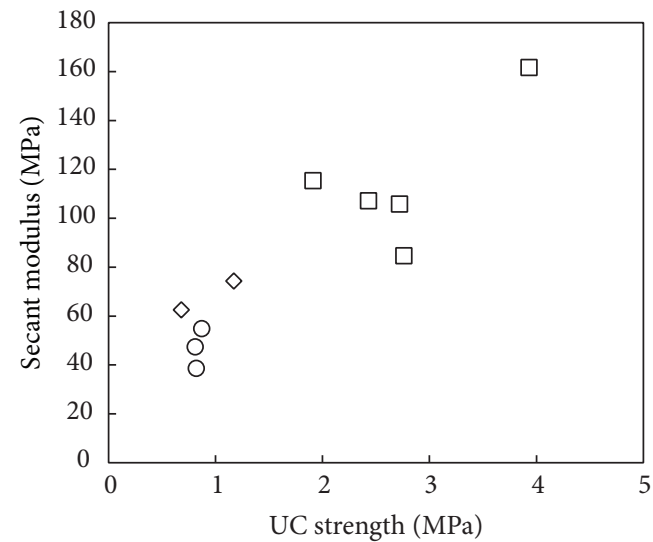

$\diamond$ Cement-treated soil $\quad \bigcirc$ Cement-lime-treated soil $\square$ Cement-fly ash-treated soil

(a)

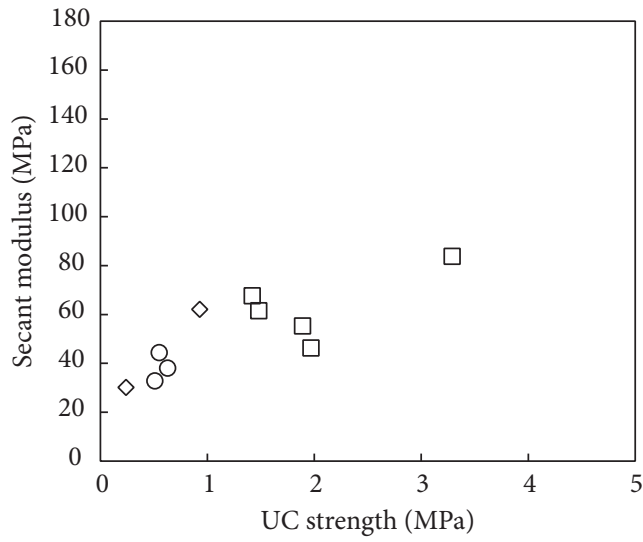

$\diamond$ Cement-treated soil $\quad \bigcirc$ Cement-lime-treated soil $\square$ Cement-fly ash-treated soil

(c)

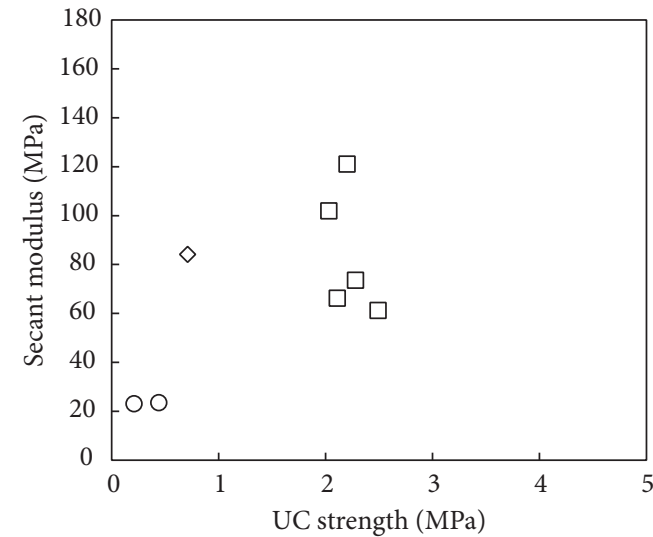

$\diamond$ Cement-treated soil $\quad \bigcirc$ Cement-lime-treated soil $\square$ Cement-fly ash-treated soil

(e)

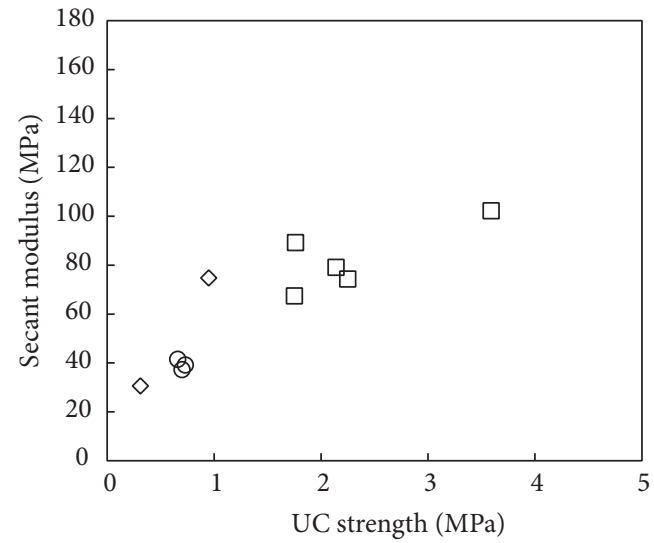

$\diamond$ Cement-treated soil $\quad \bigcirc$ Cement-lime-treated soil $\square$ Cement-fly ash-treated soil

(b)

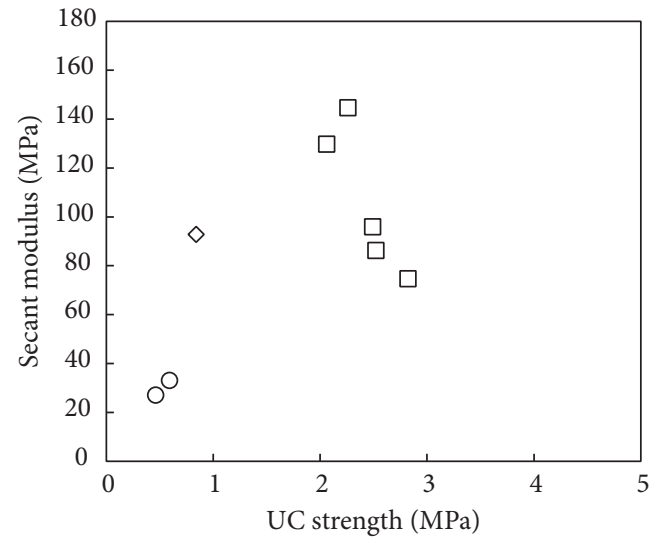

$\diamond$ Cement-treated soil $\quad \bigcirc$ Cement-lime-treated soil $\square$ Cement-fly ash-treated soil

(d)

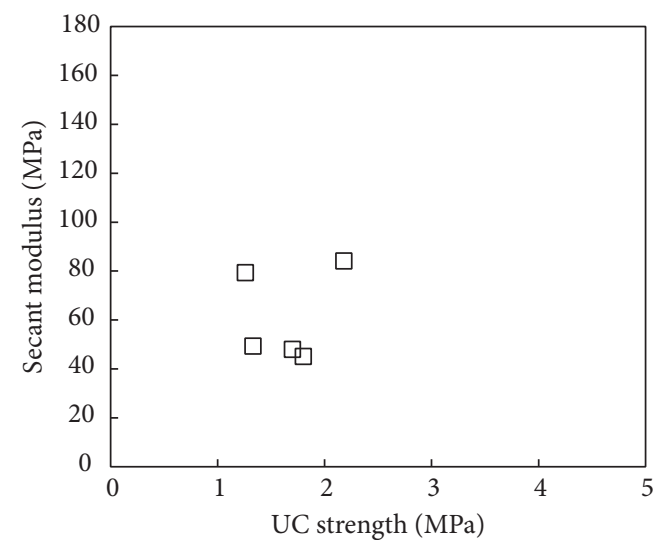

$\diamond$ Cement-treated soil $\quad \bigcirc$ Cement-lime-treated soil $\square$ Cement-fly ash-treated soil

(f)

FIGURE 9: Secant modulus versus peak UC strength for samples subjected to different freeze-thaw cycles: (a) no frost actions, (b) 1 cycle, (c) 3 cycles, (d) 5 cycles, (e) 7 cycles, and (f) 9 cycles. 


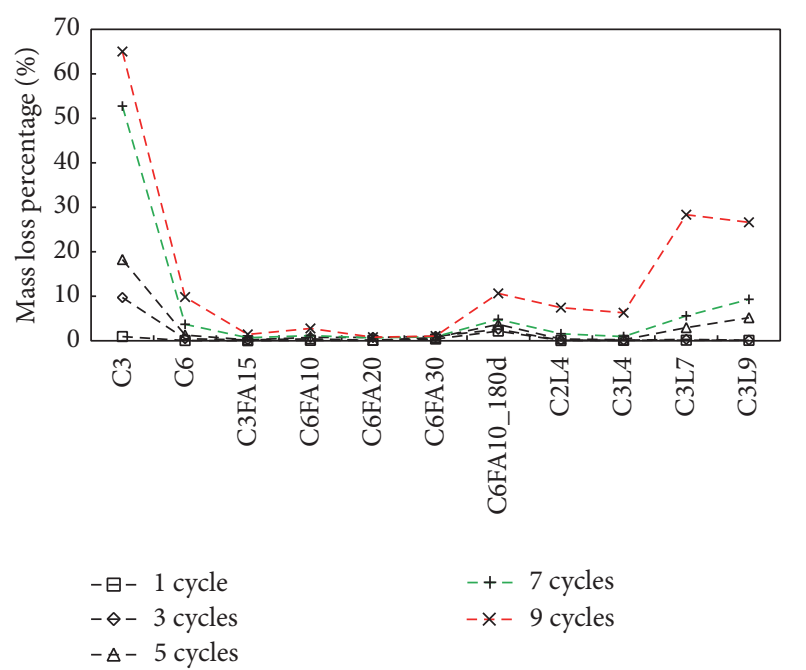

FIGURE 10: Mass loss percentage of stabilized samples after frost actions.

treatment categories decrease with the increase of the freezethaw cycles. The first two decreases (from 0 to the 1st cycle and the 1st to the 3 rd cycle) are relatively significant compared with the decreases for the rest. This means that the initial frost actions impair the materials severely.

3.4. Material Soundness and Moisture Absorption. Define mass loss percentage $=($ sample initial dry weight - sample dry weight after frost actions)/sample initial dry weight, to assess material soundness in response to the cyclic frost impact. The percentage results are shown in Figure 10. The cement-fly ash-treated samples exhibit noticeable less mass loss in contrast to the cement- and cement-lime-treated samples. For instance, after the 9th cycle, the average percentage of mass loss is $1.5 \%$ for the cement-fly ash-treated samples, $17.2 \%$ for the cement-lime-treated samples, and $37.4 \%$ for the cement-treated samples. These percentages are largely in agreement with results reported by Parsons and Milburn [37]. Their study showed, depending upon the cement dosage and soil types, mass loss of $2 \%$ to $7 \%$ for cement-treated soils, $7 \%$ to $19 \%$ for fly ash-treated soils, and $7 \%$ to $41 \%$ for lime-treated samples after 12 freeze-thaw cycles. A significant mass loss occurs to some samples, such as samples C3 of $18.26 \%$ loss of 5 cycles, C3L9 of 9.31\% loss of 7 cycles, and C3L7 of $28.34 \%$ loss of 9 cycles. Due to the significant mass reductions, these samples hardly maintained respective integrity and were not subjected to the remaining UC strength tests.

It is of interest to compare the mass losses of sample C6FA10_180d with those of sample C6FA10_28d in order to assess the effect of the curing time on the material soundness. Despite being cured longer, sample C6FA10_180d underwent a higher percentage of losses and exhibited a trend of more mass loss if the frost actions continued. These observations are in line with the relation, which was suggested by Hori and Morihiro [35] and Yarbaşi et al. [36], that existed between the material brittleness, mass loss, and strength drop as shown in Figure 9. This note is subject to insights into material

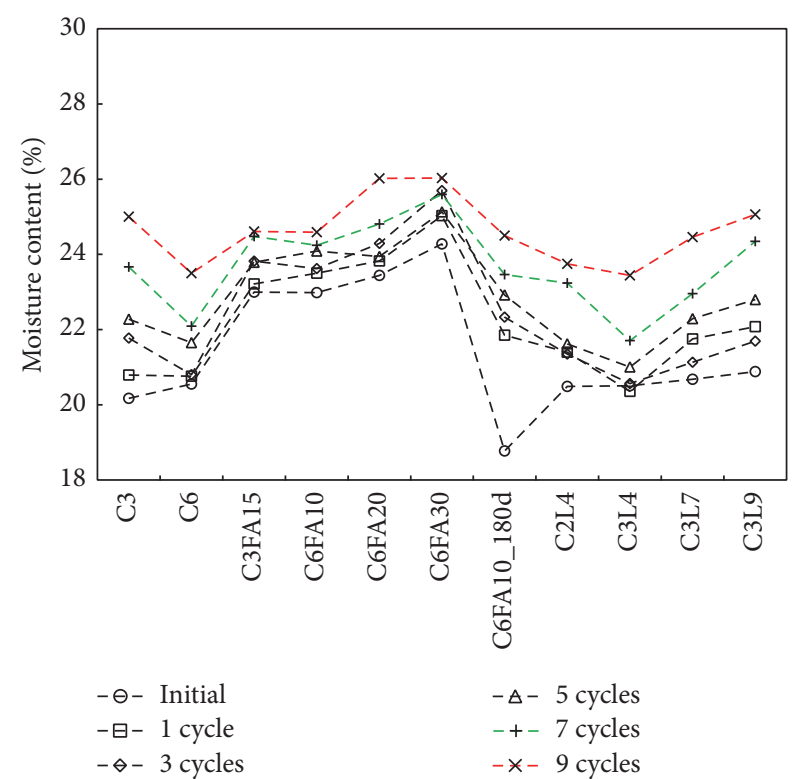

FIGURE 11: Moisture content of stabilized samples before and after frost actions.

microstructure changes detected through conducting microscopical observations such as scanning electron microscopy. These microscopical observations help shed some light on how the additives influence antifrost performance of the alluvial silt. The observational devices, unfortunately, were not accessible in the first instance and the observations are left for the next stage of studies.

The mass losses and UC strength drops are further linked to the water volume absorbed into the materials matrix during the frost actions. As discussed above, the freezing phase tends to crack or fissure the solid samples through frost heaving processes-ice lensing. The subsequent thawing phase melts the ice lenses into liquid water. A certain fraction of the sample pore space is unoccupied by the water but intruded air due to the fact that ice is $8.3 \%$ lighter than water. The formed partially saturated conditions are supposed to introduce an additional volume of water into the created cracks and fissures. The resulting increases of the water content against the frost actions are shown in Figure 11. The water contents were worked out by deducting the material mass losses. It was assumed that the samples produced in one batch have the same initial water content. This assumption enables comparisons conducted on the water contents after the frost actions. The comparisons show the following:

(i) The water contents increase with the count of the freeze-thaw cycles across all series of samples. On average, an increase of $0.23 \%$ to $0.94 \%$ is observed per two cycles for the samples tested. The degree of increase varies among the sample categories: the least for the cement-fly ash-treated samples followed by the cement- and the cement-lime-treated samples. For instance, from 7 to 9 cycles, an average increase of water content is $0.63 \%$ for the cement-fly ash-treated samples, $1.12 \%$ for the cement-lime-treated samples, and $1.37 \%$ for the cement-treated samples. 
(ii) The less noticeable changes in the water content of the cement-fly ash-treated samples agree with the less mass reduction (Figure 10) and the higher UC strength (Figure 6) of the samples.

(iii) Higher start water contents occur to the 28-day or 38day cement-fly ash-treated samples in relation to the other two treatment categories. Seeing that the three categories adopt similar levels of water contents for fresh samples (Table 3), the fly ash is acknowledged to be effective in developing samples water absorption capacity during the curing periods. A longer curing period likely offsets this effectiveness as demonstrated by sample C6FA10_180d. This sample shows less start water content in relation to the other cement-fly ash-treated samples. This means that the fly ash has nearly completed pozzolanic reactions at 180 days and became less sensitive to water presence.

\section{Conclusions}

Stabilizing the Yellow River alluvial silt through using cement, fly ash, and lime to counteract frost actions was examined. The examination was implemented through conducting Proctor compaction, unconfined compressive strength, freeze-thaw cyclic impacts, and material soundness and water absorption tests on a series of samples prepared in varying dosages. The conclusions are made as follows:

(i) Including a certain mass of additives to the silt resulted in varying compaction curves, depending on the additives and the dosages used. The cementtreated samples showed curves independent of the cement contents, whereas dosage dependency was pronounced for the curves of the cement-fly ash- and the cement-lime-treated samples. All stabilized samples gave rise to maximum dry density less than that of the silt sample and optimum moisture content in the range of $14.9 \%$ to $17.7 \%$. The cement-lime-treated samples attained optimum moisture content of up to $1 \%$ higher than the other two treatment categories.

(ii) The cement-fly ash additive was superior to the cement or cement-lime additives with respect to the development of the UC strength, secant modulus, and ductility for the Yellow River alluvial silt. The advantages were noticeable at 28 days. A range of 3 to 5 for the fly ash to cement mass ratio was plausible with respect to attaining desirable material UC strength. The cement-fly ash-treated samples are stiffer than the other two treatment categories when subjected to the same frost actions.

(iii) The first two frost actions impair the materials slightly more than the rest based on the strength development and secant moduli variation. This observation applies to all of the three stabilization categories; however, it is subject to additional test results where samples are comparable in terms of the dosage and curing time used. (iv) The cement-fly ash additive outperformed the cement or cement-lime additives with regard to capacity of counteracting the frost actions. The preferred dosage was 3\% for the cement and 15\% for the fly ash.

(v) Moisture content builds up in response to the freezethaw cycles, on average $0.23 \%$ to $0.94 \%$ increase per two cycles for the samples tested. The fly ash is effective in developing samples water absorption capacity during the curing periods.

(vi) A correlation existed between the material strength, soundness, and water absorption capacity. The higher the strength, the more noticeable the strength drop in response to the frost actions, the less the mass loss, and the less the volume of water absorbed.

\section{Competing Interests}

The authors declare that there are no competing interests regarding the publication of this paper.

\section{Acknowledgments}

This study was supported by a grant from the National Natural Science Foundation of China (51478226) and the Priority Academic Program Development of Jiangsu Higher Education Institutions.

\section{References}

[1] T.-M. Gu, Climate of North China Plain, China Meteorological Press, Beijing, China, 1991.

[2] Z.-D. Zhu, S.-Y. Liu, and H.-J. Sun, "Study of stabilized silt in Xu-Su area," Rock and Soil Mechanics, vol. 25, no. 7, pp. 11551158, 2004.

[3] J.-H. Xiao, J.-K. Liu, L.-Y. Peng, and L.-H. Chen, "Effects of compactness and water Yellow-River alluvial silt content on its mechanical behaviors," Rock and Soil Mechanics, vol. 29, no. 2, pp. 409-414, 2008.

[4] X.-G. Song, H.-B. Zhang, S.-G. Wang, Z.-X. Jia, and Y.-H. Guan, "Hydrophilic characteristics and strength decay of silt roadbed in Yellow River alluvial plain," Chinese Journal of Geotechnical Engineering, vol. 32, no. 10, pp. 1594-1602, 2010.

[5] S. Altun, A. Sezer, and A. Erol, "The effects of additives and curing conditions on the mechanical behavior of a silty soil," Cold Regions Science and Technology, vol. 56, no. 2-3, pp. 135140, 2009.

[6] K. Hazirbaba and H. Güllü, "California Bearing Ratio improvement and freeze-thaw performance of fine-grained soils treated with geofiber and synthetic fluid," Cold Regions Science and Technology, vol. 63, no. 1-2, pp. 50-60, 2010.

[7] H. Güllü and A. Khudir, "Effect of freeze-thaw cycles on unconfined compressive strength of fine-grained soil treated with jute fiber, steel fiber and lime," Cold Regions Science and Technology, vol. 106-107, pp. 55-65, 2014.

[8] T. M. Petry and D. N. Little, "Review of stabilization of clays and expansive soils in pavements and lightly loaded structureshistory, practice, and future," Journal of Materials in Civil Engineering, vol. 14, no. 6, pp. 447-460, 2002. 
[9] Z. Nalbantoğlu, "Effectiveness of class C fly ash as an expansive soil stabilizer," Construction and Building Materials, vol. 18, no. 6, pp. 377-381, 2004.

[10] A. Kumar, B. S. Walia, and A. Bajaj, "Influence of fly ash, lime, and polyester fibers on compaction and strength properties of expansive soil," Journal of Materials in Civil Engineering, vol. 19, no. 3, pp. 242-248, 2007.

[11] X. Kang, G.-C. Kang, and L. Ge, "Modified time of setting test for fly ash paste and fly ash-soil mixtures," Journal of Materials in Civil Engineering, vol. 25, no. 2, pp. 296-301, 2013.

[12] D. Ciancio, C. T. S. Beckett, and J. A. H. Carraro, "Optimum lime content identification for lime-stabilised rammed earth," Construction and Building Materials, vol. 53, pp. 59-65, 2014.

[13] N. Latifi, S. Horpibulsuk, C. L. Meehan, M. Z. A. Majid, and A. S. A. Rashid, "Xanthan gum biopolymer: an eco-friendly additive for stabilization of tropical organic peat," Environmental Earth Sciences, vol. 75, article 825, 2016.

[14] N. Latifi, C. L. Meehan, M. Z. A. Majid, and S. Horpibulsuk, "Strengthening montmorillonitic and kaolinitic clays using a calcium-based non-traditional additive: a micro-level study," Applied Clay Science, vol. 132-133, pp. 182-193, 2016.

[15] China Ministry of Construction, "Standard for soil test method," GB/T 50123-1999, China Ministry of Construction, 1999.

[16] A. Athanasopoulou, "Addition of lime and fly ash to improve highway subgrade soils," Journal of Materials in Civil Engineering, vol. 26, no. 4, pp. 773-775, 2014.

[17] J.-M. Konrad and M. Samson, "Influence of freezing temperature on hydraulic conductivity of silty clay," Journal of Geotechnical and Geoenvironmental Engineering, vol. 126, no. 2, pp. 180$187,2000$.

[18] ASTM, "Standard test method for unconfined compressive strength of compacted soil-lime mixtures," Tech. Rep. D5102, ASTM International, West Conshohocken, Pa, USA, 2009.

[19] ASTM, "Standard test methods for freezing and thawing compacted soil-cement mixtures," D560, ASTM International, West Conshohocken, Pa, USA, 2015.

[20] D. D. Tripura and K. D. Singh, "Characteristic properties of cement-stabilized rammed earth blocks," Journal of Materials in Civil Engineering, vol. 27, no. 7, Article ID 04014214, 2015.

[21] B. R. Phani Kumar and R. S. Sharma, "Effect of fly ash on engineering properties of expansive soils," Journal of Geotechnical and Geoenvironmental Engineering, vol. 130, no. 7, pp. 764-767, 2004.

[22] S. Horpibulsuk, R. Rachan, and A. Suddeepong, "Assessment of strength development in blended cement admixed Bangkok clay," Construction and Building Materials, vol. 25, no. 4, pp. 1521-1531, 2011.

[23] D. Wang, N. E. Abriak, and R. Zentar, "Strength and deformation properties of Dunkirk marine sediments solidified with cement, lime and fly ash," Engineering Geology, vol. 166, pp. 9099, 2013.

[24] Y. Yi, M. Liska, and A. Al-Tabbaa, "Properties of two model soils stabilized with different blends and contents of GGBS, MgO, lime, and PC", Journal of Materials in Civil Engineering, vol. 26, no. 2, pp. 267-274, 2014.

[25] J. Prabakar, N. Dendorkar, and R. K. Morchhale, "Influence of fly ash on strength behavior of typical soils," Construction and Building Materials, vol. 18, no. 4, pp. 263-267, 2004.

[26] T. Wu, M. Chi, and R. Huang, "Characteristics of CFBC fly ash and properties of cement-based composites with CFBC fly ash and coal-fired fly ash," Construction and Building Materials, vol. 66, pp. 172-180, 2014.

[27] M. Chrysochoou, D. G. Grubb, K. L. Drengler, and N. E. Malasavage, "Stabilized dredged material. III: mineralogical perspective," Journal of Geotechnical and Geoenvironmental Engineering, vol. 136, no. 8, pp. 1037-1050, 2010.

[28] M. A. Sakr, M. A. Shahin, and Y. M. Metwally, "Utilization of lime for stabilizing soft clay soil of high organic content," Geotechnical and Geological Engineering, vol. 27, no. 1, pp. 105113, 2009.

[29] B. Le Runigo, V. Ferber, Y.-J. Cui, O. Cuisinier, and D. Deneele, "Performance of lime-treated silty soil under long-term hydraulic conditions," Engineering Geology, vol. 118, no. 1-2, pp. 2028, 2011.

[30] D. E. Scholen, "Stabilizer mechanisms in nonstandard stabilizers," in Proceedings of the 6th International Conference on LowVolume Roads, pp. 252-260, TRB, Minneapolis, Minn, USA, 1995.

[31] S. Xu, J. Wang, and Y. Sun, "Effect of water binder ratio on the early hydration of natural hydraulic lime," Materials and Structures, vol. 48, no. 10, pp. 3431-3441, 2015.

[32] K. Natesaiyer, K. C. Hover, and K. A. Snyder, "Protected paste volume of air-entrained cement paste. Part II," Journal of Materials in Civil Engineering, vol. 5, no. 2, pp. 170-186, 1993.

[33] J. Qi, W. Ma, and C. Song, "Influence of freeze-thaw on engineering properties of a silty soil," Cold Regions Science and Technology, vol. 53, no. 3, pp. 397-404, 2008.

[34] N. N. Khoury and M. M. Zaman, "Environmental effects on durability of aggregates stabilized with cementitious materials," Journal of Materials in Civil Engineering, vol. 19, no. 1, pp. 41-48, 2007.

[35] M. Hori and H. Morihiro, "Micromechanical analysis on deterioratIon due to freezing and thawing in porous brittle materials," International Journal of Engineering Science, vol. 36, no. 4, pp. 511-522, 1998.

[36] N. Yarbaşi, E. Kalkan, and S. Akbulut, "Modification of the geotechnical properties, as influenced by freeze-thaw, of granular soils with waste additives," Cold Regions Science and Technology, vol. 48, no. 1, pp. 44-54, 2007.

[37] R. L. Parsons and J. P. Milburn, "Engineering performance of stabilized soils," Transportation Research Record, vol. 1837, pp. 20-29, 2003. 

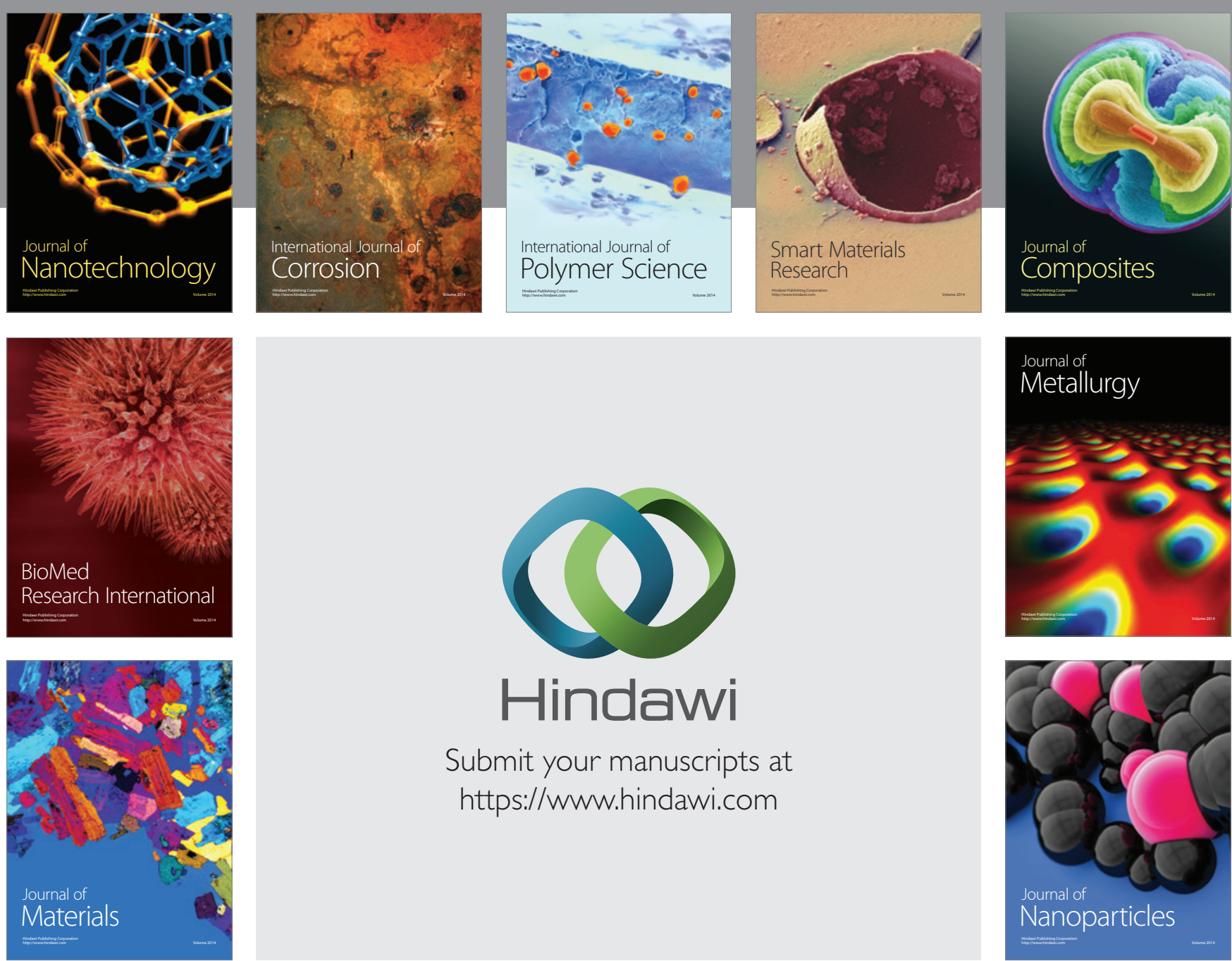

\section{Hindawi}

Submit your manuscripts at

https://www.hindawi.com

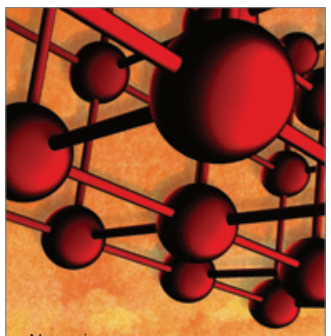

Materials Science and Engineering
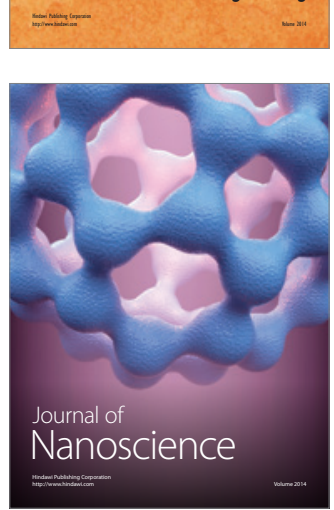
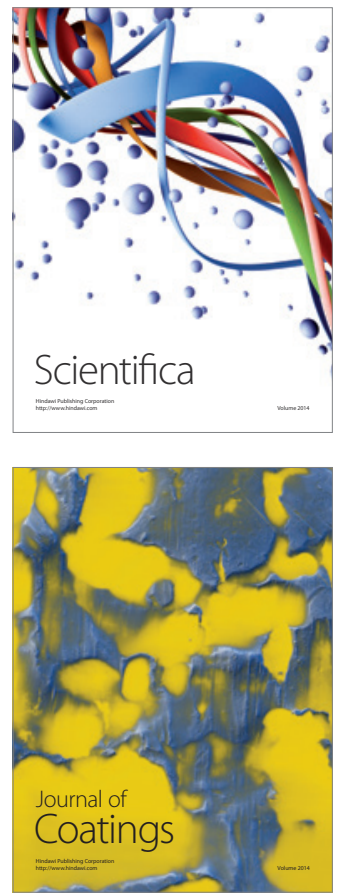
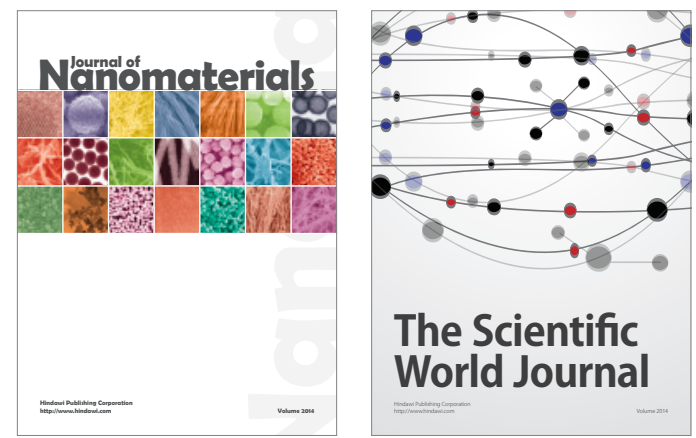

The Scientific World Journal
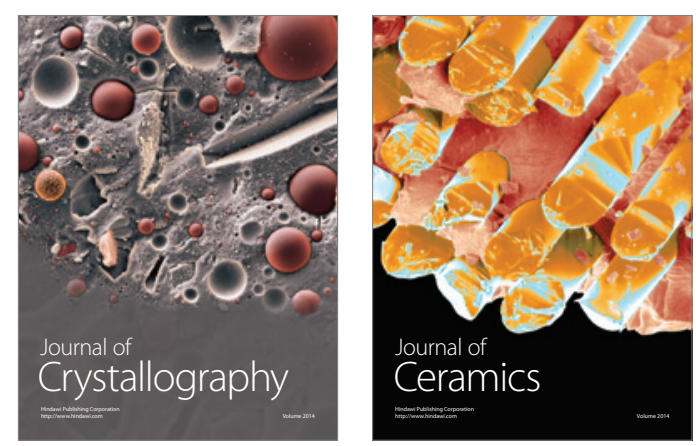
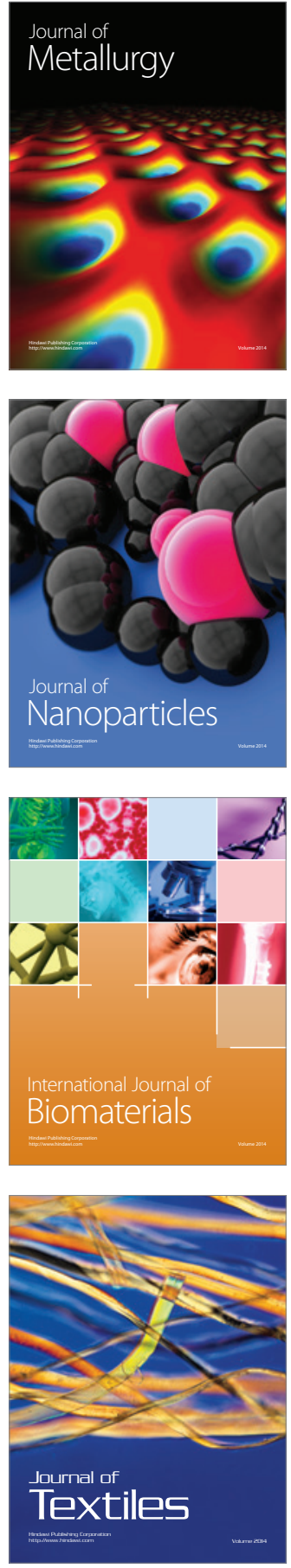